\title{
Management Mode of Scientific Research Projects Based on PDCA
}

\author{
Ming Cao \\ CCTEG XI'AN Research Institute, Xi'an, 710077, China \\ Caom1979@126.com
}

\begin{abstract}
The difference is analysed detailedly between research management and production management from three aspects in the paper. It constructs new management mode of scientific research projects based on PDCA, and expounds the mode's workflow in the process of projects implementation.
\end{abstract} \section{PDCA}

Keywords-Scientific Research Projects; Management Mode;

\section{INTRODUCTION}

Quality Management (QM) includes all activities of the overall management function that determine the quality policy, objectives and responsibilities, and implements them by means such as quality planning, quality assurance, quality control and quality improvement, within the quality system.

The products of Scientific Research Projects are scientific research achievements, which must carry out quality management to improve the quality of scientific research.

\section{BASIC PRINCIPLE OF PDCA CYCLE}

The concept of PDCA cycle is brought up by William Edwards Deming who is famous quality management expert. PDCA cycle is the basic procedures of total quality management, its connotation includes:

$\mathrm{P}$ (Plan)--Identifying which quality standards are relevant to the project and determining how to satisfy them.

D (Do)--Execute the plan.

$\mathrm{C}$ (Check)--Evaluate the results.

A(Action)--Standardization and further promotion.

The entire process of total quality management activities is the process of making the quality plan and implementation, which is cycling according to the PDCA without halt, shown as Figure.1.

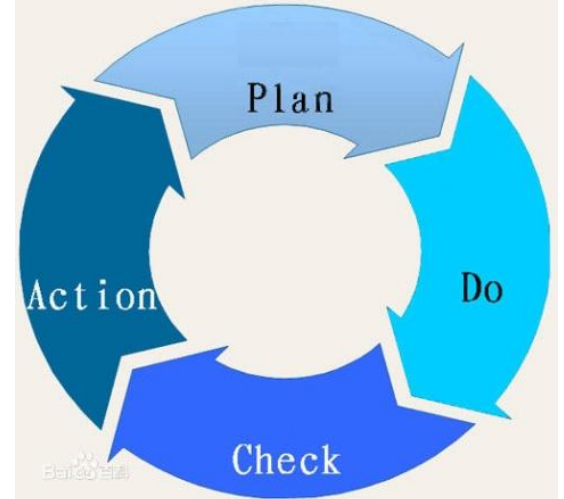

Figure.1. PDCA Cycle

\section{DIFFERENCE BETWEEN SCIENTIFIC RESEARCH MANAGEMENT AND PRODUCTION MANAGEMENT}

The characteristics of scientific research projects decide its quality target is difficult to control by the method of quantitative, only the combined method of qualitative and quantitative. According to the characteristics of the scientific research projects, the main purpose of quality control based on management process is reaching high quality in low cost and striking a balance between the management and the effect within the reasonable time. Difference between research management and production management shown as Figure. 2

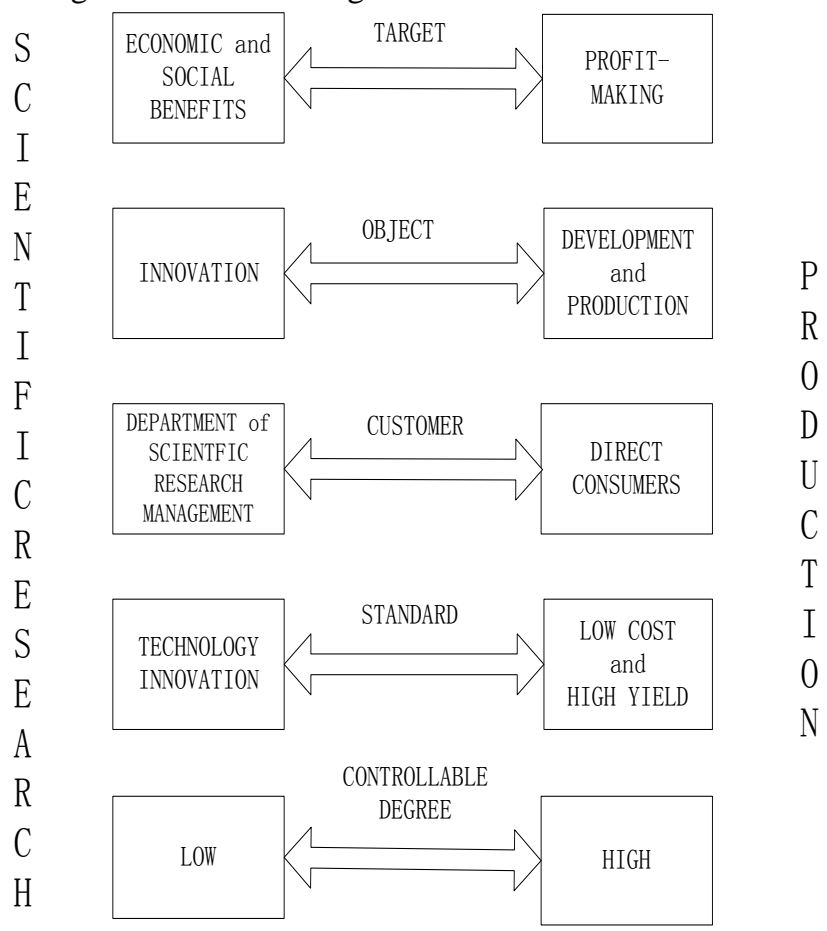

Figure.2. Comparison between Scientific Research Management and pProduction Management

Traditional quality management is not adapting to the scientific research activities, the inadaptation shows in three respects: 


\section{A. It Lacks Quality Control Points in the Process of Scientific Research.}

Quality control point is key point of collecting quality feedback information and issuing quality control instructions. Traditional quality management had made quality supervision by monitoring a number of locked and stable quality control points; the essence of quality control point is the strength point and the most impotant operation guarantee of traditional quality management working. Scientific research is a kind of activities of exploring the unknown, which could obtain a number of negative or affirmative conclusions through arguing the hypothesis, and then form new hypothesis, argue the new hypothesis, obtain new conclusions.......continuous circle unless getting final results. Traditional quality management could not lock the stable quality control points in this uncertained process.

\section{B. It Lack Stable Evaluation Criterion in the Process of Scientific Research.}

Traditional quality management measure objects by means of a set of stable evaluation criteria, that is an indispensable tool for running of traditional quality management.Research process is formed of a concatenation of hypothesis which have unstable evaluation criteria, the evaluation criteria could change with research conditions or knowledge changing, that is to said, research process lack a stable evaluation criterion, which make evaluation criterion unavailable for traditional quality management.

\section{Research Process is Difficult to Visually Verify.}

The objects faced to traditional quality management must be intuitive to understand, that could straightforward carry out observation, calculation, comparison, analysis and evaluation to the objects.Scientific research need high intelligence, it's part could be expressed directly, but the core part--the thinking process of forming hypothesis-hide itself, which make traditional quality management verify nothing.

\section{MANAGEMENT MODE OF SCIENTIFIC RESEARCH PROJECTS BASED ON PDCA}

According to the total quality management process and the characteristic of scientific research projects, we divide quality control of scientific research projects into four stages:

\section{A. Quality Control of Scientific Research Projects Planning Stage}

1) Appraisement, overall quality control for projects

Based on the early survey, the department of project application formulates "Feasibility Research Report" according to required format and contents. Before signing the contract of project approval, the experts group will appraise the projects applied; the appraised contents include necessity, feasibility, research contents and targets, economic and technical norms, project implementation plan, appropriation budget, risks, and so on. Experts will decide whether the project approved, and put forward a clear opinion about the problems existed.

2) Signing the contract of project approval, targets control.

Signing the contract of the projects passed evaluation between the department of $R \& D$ management and project application, which will determine the research contents and targets, economic and technical norms, project implementation plan, appropriation budget, quality requirements of each stage, etc.

\section{B. Quality Control of Projects Implementation Stage}

Quality control mechanism in scientific research projects implementation stage shown as Figure.3, which works through control system of indirect control layer. According to the cybernetics theory, control subject is project leader and the department of implementing project, control target is project contract and target tasks of each stage, it updates control target using regulator on the basis of information feedback.

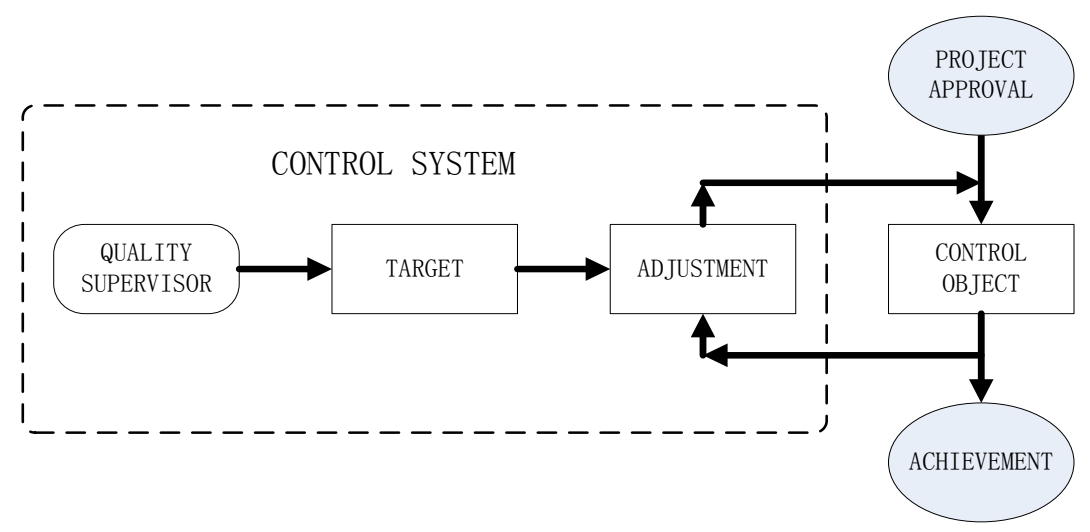

Figure.3. Quality control mechanism of Science Research Project 


\section{1)Appraisement of implementation plan}

After project approval, researchers should write implementation plan based on the contract signed, the experts group organized by the department of $R \& D$ management will appraise the technical routes.

\section{2)Process control}

To get hold of the research progress, department of $R \& D$ management check all the scientific research projects in every July and December. For the key projects, the progress of the project could be mastered at any time. If there are the problems in the implementation stage, it organizes experts to make constructive suggestions at once.

\section{Quality control of projects acceptance stage}

Acceptance stage is the last stage of project life cycle, which confirms wether the project has reached the expected requirements. Quality management point in this stage is a qualified control.

While the projects were completed, the departments of $R \& D$ management organize experts to check and accept the research production according to the contract of project approval, and control the completing quality.

\section{Continuous improvement of Scientific Research Projects}

The goal of continuous improvement of scientific research projects is enhance the ability of meeting the quality requirements. In the process of projects implementing, quality improvement is by means of continuously improving the methods of research and analysis. Continuous improvement is the improvement of process, the positive improvement and preventive improvement. The departments of $R \& D$ management pay close attention to the project schedule at any time, and organize experts to guide project improvement timely. The implementation process of the continuous improvement can be summarized as PDCA cycle, as is shown in Figure.4.

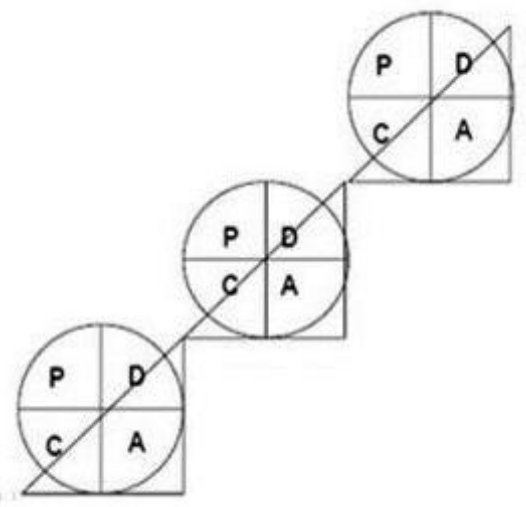

Figure.4. PDCA Cycle of Science Research Project

\section{V.CONCLUSION}

- Basic principle of PDCA cycle is introduced in this paper.

- It detailedly analyse the difference between research management and production management from three aspects, and come to the conclusion that normal method of production management isn't appropriate for management of scientific research projects.

- According to the total quality management process and the characteristic of scientific research projects, it constructs new management mode of scientific research projects based on PDCA, and introduce the mode's workflow in detail.

\section{REFERENCES}

[1] Fang Yong, Zheng Yinxia, Marsili, “Application and Development of Total Quality Management in Research Management", SCIENCE OF SCIENCE AND MANAGEMENT OF S. \& T., vol.35, no.2, pp. 28-38, 2014

[2] López-Mielgo N, Montes-Peón M J, Vázquez-Ordás JC, “Are quality and innovation management conflictingactivities" Technovation, vol.29, no.8, pp.537-545, 2009.

[3] Prajogo D I, Hong S W., "The effect of TQM on per-formance in R\&D environments: A perspective from South Korean firms", Technovation, vol.28, 2008, pp. 855-863, no. 12 .

[4] Zhang Bao-sheng, "LV Hong-di. Research on Quality Control of Science Research Project in Implementation Process", Future and Development, pp. 13-17, July 2013.

[5] Chong A Y, Keng-Boon O, Binshan L, et al., "TQM, knowledge management and collaborative commerce adoption: A literature review and research frame-work" Total Quality Management \& Business Excel-lence, vol.21, pp. 457-473, May 2010. 